\title{
FINITE ELEMENT ANALYSIS ON DIESEL TANK OF SIX WHEELED TRUCK
}

\section{BHANU PRAKASH M J, PRAVEENKUMARA B M, RAJESH KUMBARA S K \& MAMATHA Y P}

Department of Mechanical Engineering, Vidyavardhaka College of Engineering, Mysuru, India

ABSTRACT
The main objective of this project is to investigate the existing and new design of fuel tank for trucks with respect to
design reliability and real time performance. Another objective is to improve design by adopting shape and size
optimismation concept through FEA. The real time performance of tank was inspected by collecting the data from
workshop and also observing the actual components condition. Further the design improvement was done by carried out
the finite element analysis (FEA) of fuel tank structure and its mounting bracket at the various load conditions like 2 G \&
3G. The $3 D$ modelling was done by using Pro-E wildfire software. The FEA analysis of tank structure and mounting
bracket was carried-out by using Pro-Mechanica software. The design improvement was done by strengthing the
structure and introducing better mounting concept to aviod vibration and catastropic failure.
KEYWORDS: Finite Element Analysis, Catastrophic Failure, Reliability, Real Time

Received: Jun 06, 2020; Accepted: Jun 26, 2020; Published: Aug 25, 2020; Paper Id.: IJMPERDJUN2020878

\section{INTRODUCTION}

In every automobile vehicle, storage of fuel is an important aspect. Fuels are stored in the tanks and are mounted on frames of vehicle. Capacity of the fuel tanks varies with each vehicle depending on the application. Basically truck vehicles have fuel tank capacity of more than 150 liters. Design of fuel tanks is also a complex task. There are many shapes of tanks like, cylindrical, rectangular, D-shaped tank. Most preferred tanks are either cylindrical or rectangular depending on the volume of the fuel required for particular. The rectangular tanks are preferred for maximum volume of fuel intake. In trucks, most of the design of fuel tank is cylindrical because of visual and stylish look of the vehicle. The fuel tanks are mounted on the frame of the vehicles using mounting brackets.

There are various systems in vehicle such as exhaust system, fuel system, hydraulic system etc. Among all the systems, the fuel system is most important and critical one. The fuel system of automobile vehicles should perform within major safety parameters related to the importance of flammable substances such as diesel fuels which is extensively consumed worldwide. Determining the location, choosing required shapes as per required volume is also important while designing a fuel tank for every vehicle. To mount the fuel tank/diesel tank to truck frame the use of brackets and straps are required.

\section{Baffle Plate}

In design of any large quantity fuel tanks, baffle plates are inserted in the fuel tanks to avoid the fuel sloshing inside the tank. The fuel sloshing is one the main problem in the partially filled fuel tanks because when the vehicle accelerates or deaccelerates a fast movement of fuel tank be seen. Due to this movement stability of the whole fuel tank assembly will bw low. Based on the company designs the baffle plates design also gets changes. Considerably their may be two to three baffle plates inside the fuel tank of truck vehicle. Fig 1.2 shows the baffle plates present inside the fuel/ diesel tank. 
There is a continuous improvement in the automobile industry in modification of mechanical parts in order to attain better performance. In automotive vehicles like trucks, the fuel tank rests on mounting brackets which are connected to the main-frame. Important consideration in designing a diesel fuel tank are determining placement, choosing the shape and calculating the required volume. The main objective of this paper goes with improvising the existing design.

- Comparing existing fuel tank material with other suitable materials.

- Preventing corrosion problem in the tank to increase the overall service life.

\section{LITERATURE SURVEY}

Umesh s. ghorpade et al., [2012.] has investigated on finite element analysis of engine bracket of car and natural frequency will be determined. Engine bracket has been designed as a framework to support engine. The main concern is for vibration and fatigue of engine bracket which may lead to structural failure if resulting vibration and stress are excessive.[1]

Mohd. Tanveer akhtar et al., [2015] this paper has stated that the fuel tank is safe container for automobile since it contains flammable fluids which may leads to explosion. A good fuel system is decided on correct selection or construction of the tank, tank location, correct venting, spillage and leakage dispersal, and care. So this project is undertaking an investigation on commercial vehicles fuel tank design.[2]

Kandasamy et al., [2014] this project deals on effectiveness of different design of baffles for partly filled fuel tank. In road tankers the free surface of liquid cargo may experience a large excursion for very small motion of the container. This problem is common in automobile, aircrafts and tankers. To study the anti-slosh properties of different baffles design under different cargo loads a 3D model of partly filled fuel tank is developed.[3]

Murat kucumen et al., [2014] has investigated that the fuel system of automobile vehicle should be perform with major safety parameters in order to maintain an overall safety standard ECE R34 directive are represented by the united automotive authority. This study propounds the importance of material selection and packaging of fuel system components designed for liquid fuel verities according to ECE R34 directive definition.[4]

\section{METHODOGOLGY}

The initial stage of project is the design data extraction in workshop. After the validation of design, the complete 3D model of existing and proposed design was created by using Pro-E software. The finite element analysis of the existing and proposed design was carried out by using Pro-mechanica software. The comparative study was made and conclusion were presented. Figure 1 shows the flow chart of work. 


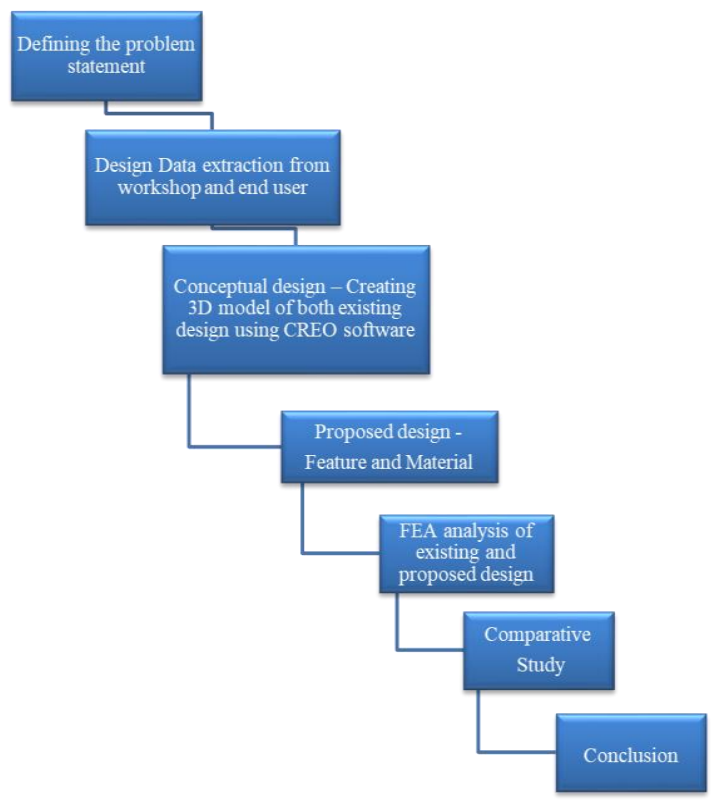

Figure 1: Methodology Flow Chart.

\section{DIGITAL MODELING}

Figure 2 shows the 3D model of existing design of fuel tank with mounting bracket. This modeling is completely done by using pro-E software. Finite Element Analysis (FEA) is carried out by using Pro-Mechanica.

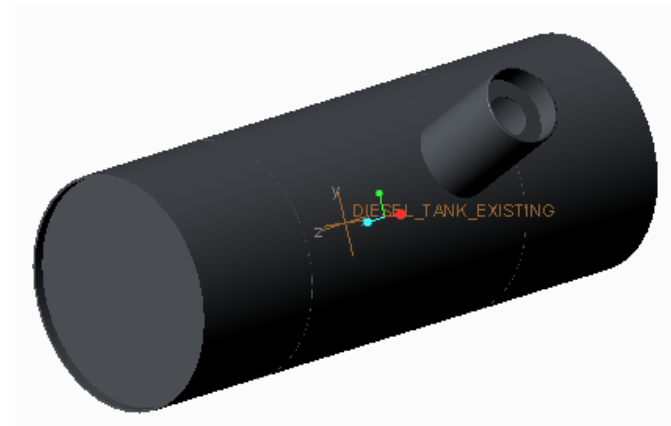

Figure 2: 3D model of Existing Diesel.

\section{THEORETICAL CALCULATIONS}

Volume of the Tank

Data: - Inner diameter $=420 \mathrm{~mm}=0.420 \mathrm{~m}$

Inner Radius $=0.210 \mathrm{~m}$

Length of the tank $=1.150 \mathrm{~m}$

Wall thickness of tank $=0.005 \mathrm{~m}$

- Cylinder Volume Formula

$$
\begin{aligned}
& V=\pi r^{2} h \\
& \mathrm{~V}=3.14 \times(0.210)^{2} \times 1.150
\end{aligned}
$$




\section{$\underline{V=0.159 .3 m^{3}}$}

- Converting Volume to Liters

$0.159 .3 \mathrm{~m}^{3} \times 1000=159.3$ liters

The capacity of the tank $=1601$ ts (approx.)

\section{Weight Calculation}

It includes the capacity of the tank and the self-weight of tank.

Material of the tank $=$ Steel

Density of the Steel $=7890 \mathrm{~kg} / \mathrm{m}^{3}$

Capacity of the tank $=1601$ ts

Diesel mass density $=865 \mathrm{~kg} / \mathrm{m}^{3}$

Converting $\mathrm{kg} / \mathrm{m}^{3}$ to $\mathrm{kg} / \mathrm{liter}=865 \mathrm{~kg} / \mathrm{m}^{3}$

$$
=0.865 \mathrm{~kg} / \mathrm{liter}
$$

So for 160 liters, diesel mass is $138.4 \mathrm{~kg}$

Self-Weight formula for tank

Self-weight $=2 \pi r l t \times \rho$

$$
\begin{aligned}
& =2 \times 3.14 \times 0.210 \times 1.150 \times 0.005 \times 7890 \\
& =59.8 \mathrm{~kg}
\end{aligned}
$$

(Without including inside baffles and side plates)

Mass of side plates of the fuel tank

$=\pi \times r^{2} \times t \times \rho=3.14 \times(0.210)^{2} \times 0.005 \times 7890$

$=5.5 \mathrm{~kg}($ one side $)+5.5 \mathrm{~kg}$ (other side $)$

Mass of side plates of the fuel tank $=11 \mathrm{~kg}$

Mass of the baffle plates $=7 \mathrm{~kg}$

Self-weight including baffles and the side plates $=78 \mathrm{~kg}$

Total Mass of the tank $=138 \mathrm{~kg}+78 \mathrm{~kg}$

$$
=216 \mathrm{~kg}
$$

Total Weight of Tank $=2118.96 \mathrm{~N}$ (this load will be shared to two brackets equally)

Internal Pressure of Diesel Tank

Pressure Equation $(\mathrm{P})=\rho \times g \times h$ 
Where,

$$
\begin{aligned}
& \rho=\text { Diesel Density }\left(\mathrm{kg} / \mathrm{m}^{3}\right) \\
& \mathrm{g}=\text { Acceleration due to gravity }\left(\mathrm{m} / \mathrm{s}^{2}\right) \\
& \mathrm{h}=\text { height of fluid column }(\mathrm{m})
\end{aligned}
$$

\section{Standard Values}

Diesel mass density $=865 \mathrm{~kg} / \mathrm{m}^{3}$

Converting acceleration due to gravity from $\mathrm{m} / \mathrm{s}^{2}$ to $\mathrm{g}$

$$
\mathrm{g}=9.8 \mathrm{~m} / \mathrm{s}^{2}=0.9993 \mathrm{~g}
$$

\section{Tank Dimension}

Outer diameter $=430 \mathrm{~mm}=0.430 \mathrm{~m}$

Height of the fluid column $=0.420 \mathrm{~m}$

Converting diesel density $865 \mathrm{~kg} / \mathrm{m}^{3}$ to $8485.6 \mathrm{~N} / \mathrm{m}^{3}$

Pressure $(\mathrm{P})=8485.6 \times 0.420 \times 0.9993$

Pressure $(\mathrm{P})=3561 \mathrm{~N} / \mathrm{m}^{2}$

\section{ANALYSIS ON FUEL TANK}

The fuel tank shape is cylindrical and analysis is carried out using pro-mechanica software. The theoretically calculated internal pressure is given as load for the fuel tank to check whether it withstands the internal pressure. The thickness of the tank is $5 \mathrm{~mm}$. Loading and constraints of the bracket is shown below.

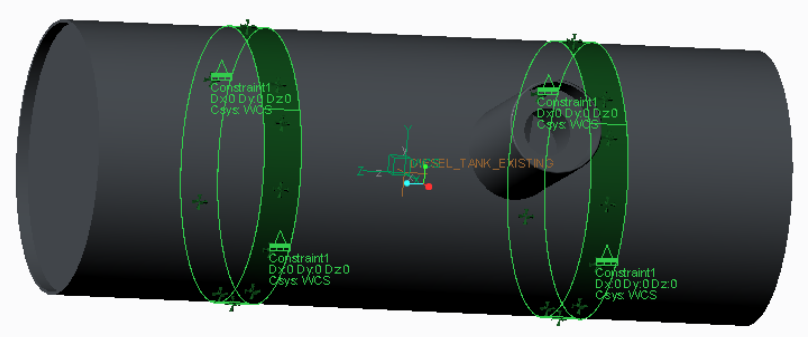

Figure 3: All DOF Constraints to Fuel Tank.

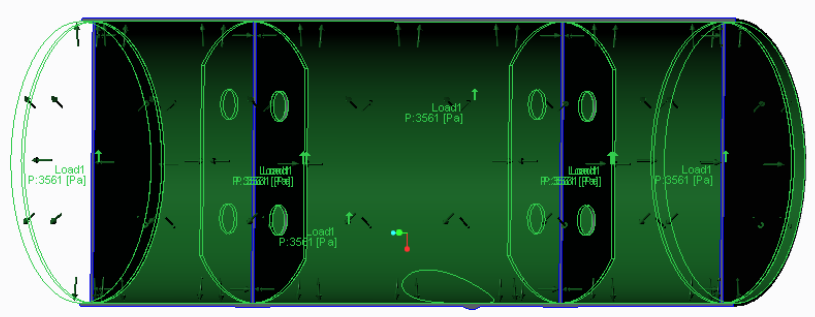

Figure 4: Internal Pressure Given to Fuel Tank. 


\section{Tank Material: Steel}

The existing material using for the fuel tank is steel. Here steel is the material considered for the analysis and material properties is given in below table. The von-mises stress, deformation and shear stress is obtained for the tank.

Table 1: Material Properties of Steel

\begin{tabular}{|l|c|}
\hline Mechanical Properties & Material - Steel \\
\hline Young's Modulus & $2.1 \mathrm{E}^{5} \mathrm{~N} / \mathrm{mm}^{2}$ \\
\hline Density $(\boldsymbol{\rho})$ & $7890 \mathrm{~kg} / \mathrm{m}^{3}$ \\
\hline Poisson's Ratio $(\vartheta)$ & 0.3 \\
\hline Yield Strength & $210 \mathrm{MPa}$ \\
\hline
\end{tabular}

Tank Material: High Density Polyethylene (HDPE)

High-density polyethylene is a polyethylene thermoplastic used in many applications like, corrosion resistant piping, fuel tank for vehicles, corrosion protection for steel pipe lines. Here, the above material is considered for the analysis of existing diesel tank. The stress and deformation result is shown in the analysis.

Table 2: Material Properties of HDPE

\begin{tabular}{|l|c|}
\hline Mechanical Properties & Material - HDPE \\
\hline Young's Modulus & $900 \mathrm{~N} / \mathrm{mm}^{2}$ \\
\hline Density $(\rho)$ & $950 \mathrm{~kg} / \mathrm{m}^{3}$ \\
\hline Poisson's Ratio $(\boldsymbol{\vartheta})$ & 0.46 \\
\hline Yield Strength & $26 \mathrm{MPa}$ \\
\hline
\end{tabular}

Tank Material: Aluminum 6061

The aluminum 6061 is an alloy that majorly contains the composition of alloying element such as magnesium and silicon. This material has its own application because of light weight. It is mainly used in construction of aircraft parts like wings and fuselages, also used in automotive parts like chassis of the Audi A8 vehicle. Here this material is considered for the tank application and the analysed result is shown.

Table 3: Material Properties of AL 6061

\begin{tabular}{|l|c|}
\hline Mechanical Properties & Material - Al 6061 \\
\hline Young's Modulus & $69 \mathrm{GPa}$ \\
\hline Density $(\rho)$ & $2700 \mathrm{~kg} / \mathrm{m}^{3}$ \\
\hline Poisson's Ratio $(\vartheta)$ & 0.33 \\
\hline Yield Strength & $55 \mathrm{MPa}$ \\
\hline
\end{tabular}

\section{RESULTS AND DISCUSSION}

The result of the tank with different materials is shown in this chapter. The materials are steel, aluminium and HDPE. The results like vin-mises stress, deformation and shear stress of all the three materials are shown. 
Material: Steel

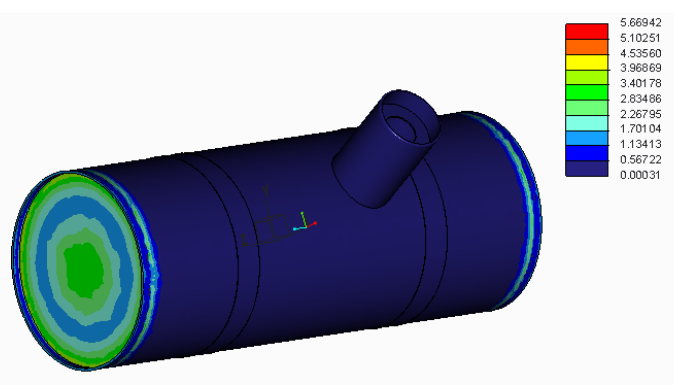

Figure 5: Von-Mises Stress is 5.66MPa.

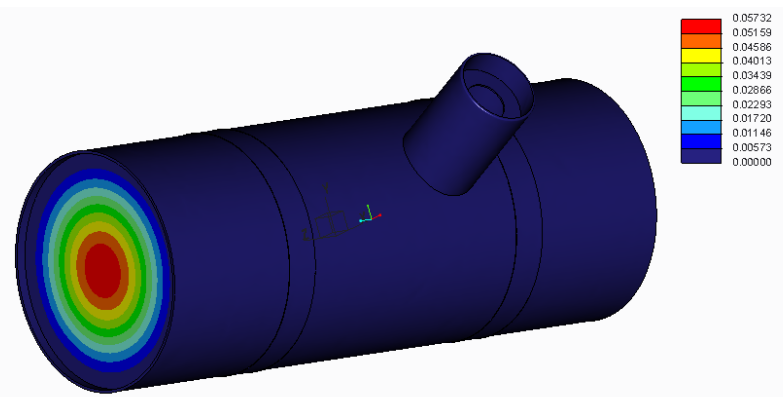

Figure 6: Deformation is $0.057 \mathrm{~mm}$.

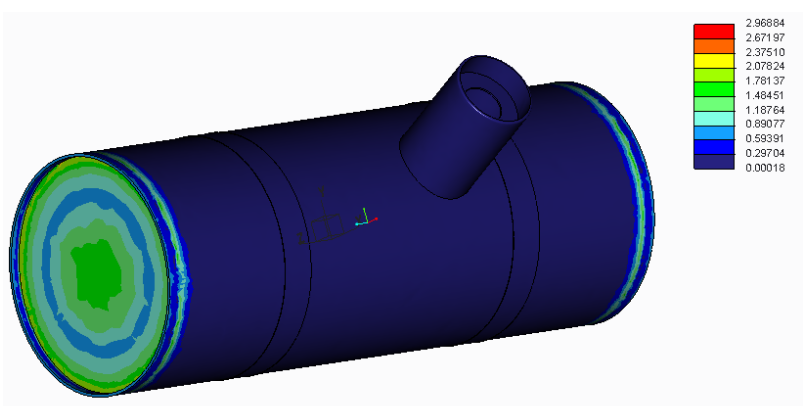

Figure 7: Shear Stress is 2.96MPa.

Table 4: Results of Steel Material

\begin{tabular}{|l|c|}
\hline \multicolumn{1}{|c|}{ Parameter } & Cylindrical Tank \\
\hline Von-mises stress(MPa) & 5.66 \\
\hline Deformation(mm) & 0.057 \\
\hline Shear stress(MPa) & 2.96 \\
\hline
\end{tabular}

Material: High Density Polyethylene

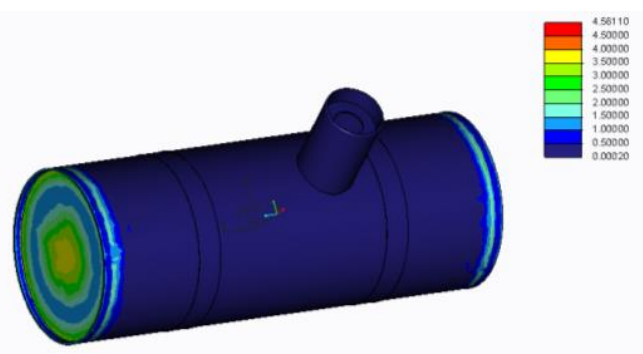

Figure 8: Von-Mises Stress is 4.56MPa. 


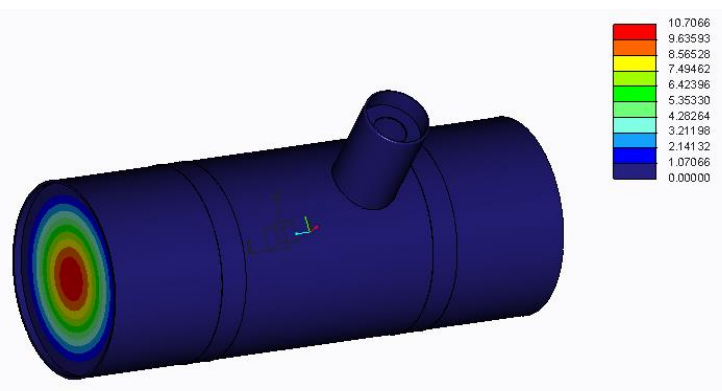

Figure 9: Displacement is $10.7 \mathrm{~mm}$.

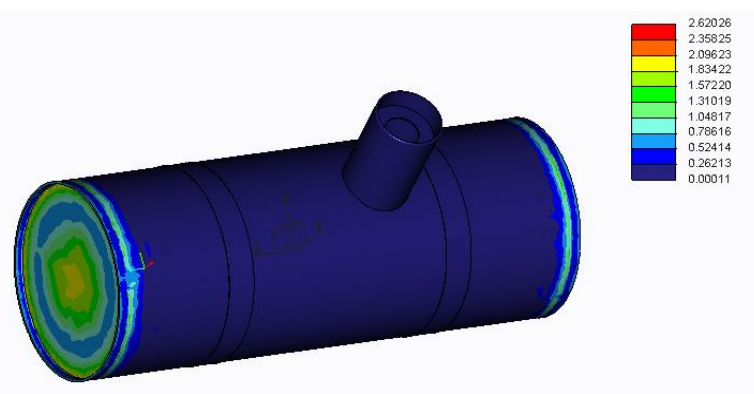

Figure 10: Shear Stress is 2.62Mpa.

Table 5: Results of HDPE Material

\begin{tabular}{|l|c|}
\hline \multicolumn{1}{|c|}{ Parameter } & Cylindrical Tank \\
\hline Von-mises stress(MPa) & 4.56 \\
\hline Deformation(mm) & 10.7 \\
\hline Shear stress(MPa) & 2.62 \\
\hline
\end{tabular}

Material: Aluminium 6061

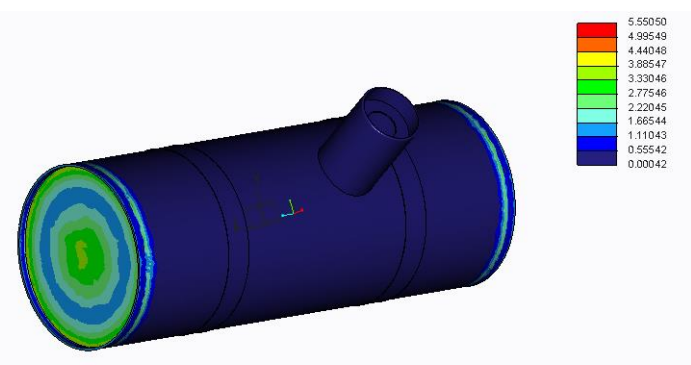

Figure 11: Von-Mises Stress is 5.55MPa.

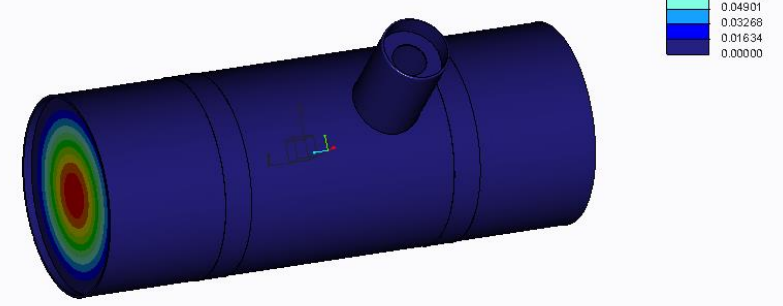

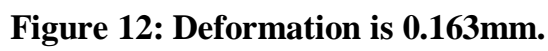




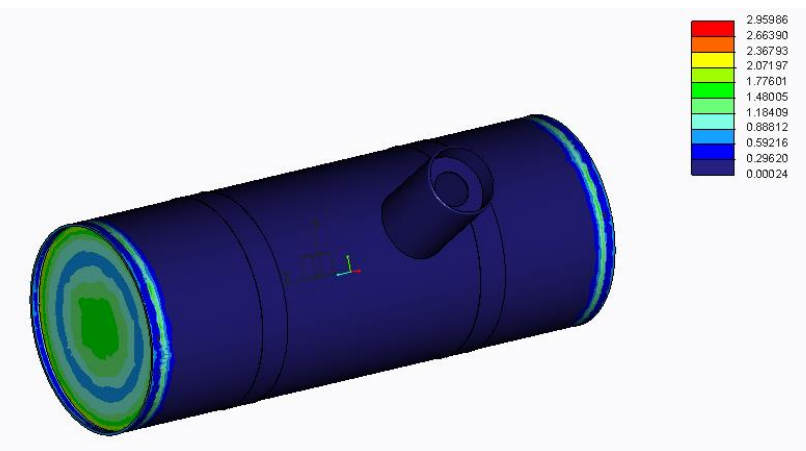

Figure 13: Shear Stress is 2.95MPa.

Table 6: Results of Al 6061 Material

\begin{tabular}{|l|c|}
\hline \multicolumn{1}{|c|}{ Parameter } & Cylindrical Tank \\
\hline Von-mises stress(MPa) & 5.55 \\
\hline Deformation(mm) & 0.163 \\
\hline Shear stress(MPa) & 2.95 \\
\hline
\end{tabular}

\section{Results of Diesel Tank}

The analysis made on the diesel tank is by considering three different kinds of materials that can be suited for tank material. The materials are of steel, high density polyethylene and aluminium. The stress and deformation results obtained for the all the above three materials is shown in below tables.

Table 7: Results of Stress and Deformation of Three Different Tank Materials

\begin{tabular}{|l|c|c|c|}
\hline \multicolumn{1}{|c|}{ Parameter } & Steel & HDPE & Aluminium \\
\hline Von-mises stress(MPa) & 5.66 & 4.56 & 5.55 \\
\hline Deformation(mm) & 0.057 & 10.7 & 0.163 \\
\hline Shear stress(MPa) & 2.96 & 2.62 & 2.95 \\
\hline
\end{tabular}

The results of stress and deformation of different tank materials is shown. The stress values of three materials is almost similar and deformation in HDPE tank materials is higher than compared to other two materials and several layers of HDPE can be material can be mounted on the tank to avoid excessive deformation.

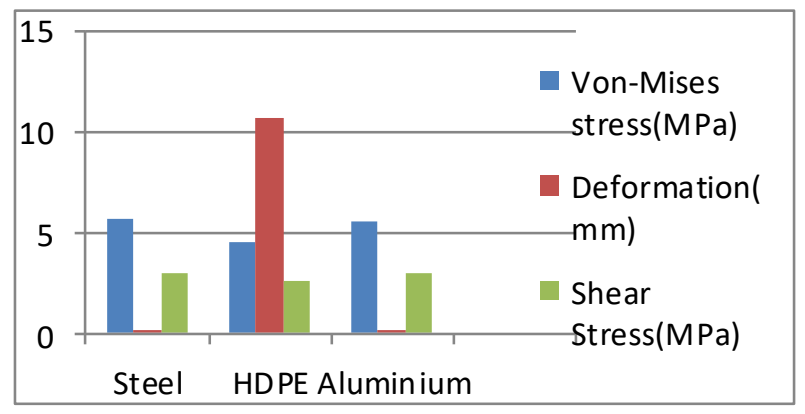

Figure 14: Result Chart of Three Tank Material.

In the diesel tank of truck vehicle three different types of materials is chosen and has analyzed to know the values of stress acting. The materials are steel, aluminum 6061 and high density polyethylene. The self-weight of the tank with respect to given materials are shown in below table. 
Table 8: Properties of Tank Materials with Self-Weight

\begin{tabular}{|l|c|c|c|}
\hline \multicolumn{1}{|c|}{ Properties } & Steel & Aluminum & HDPE \\
\hline Density(kg/m $\left.{ }^{3}\right)$ & 7890 & 2700 & 950 \\
\hline Yield strength(MPa) & 210 & 55 & 26 \\
\hline Tank capacity(liters) & 160 & 160 & 160 \\
\hline Self-weight(kg) & 77 & 27.25 & 9.77 \\
\hline
\end{tabular}

By using either aluminum or HDPE as a tank material we can get better performance of the vehicle and also the fuel efficiency will be better. The below bar graph shows the self-weight of the tank upon different thickness of tank material.

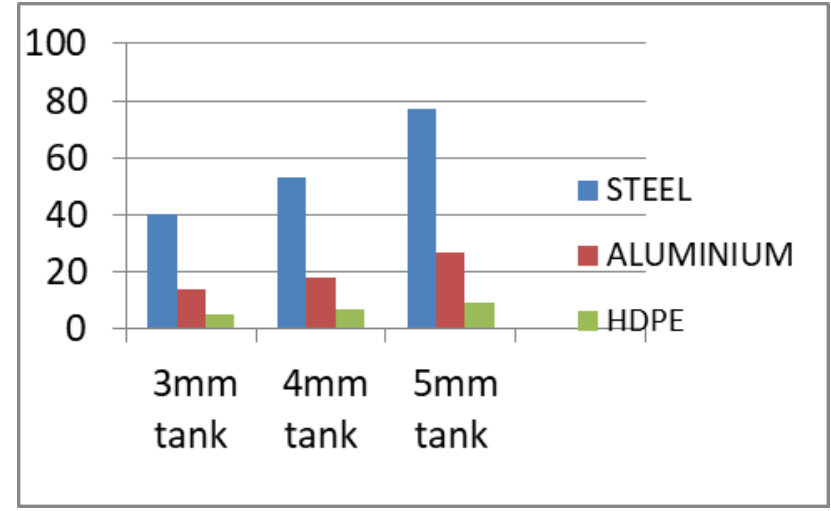

Figure 15: Self Weight of the Tank on Different Thickness.

\section{CONCLUSIONS}

In this topic static structural analysis is carried out for fuel tank of truck vehicle. The improvement based on new idea is made to improve the mounting capacity for the bracket. The material used for tank is largely steel and different two materials are been proposed to reduce the weight of the tank and to improve the performance of the vehicle.

HDPE is a plastic material so that the density is also low compared to other two materials. The deformation is slightly high in this and it can be overcome by adding extra layers of material to give more strength and to attain less deformation.

\section{ACKNOWLEDGMENT}

I consider this as a great privilege to present this paper and I take this opportunity to thank all those who made this endeavor a success.

I thankful to Head of the Department, Principal and management of VVCE, without their help this paper would not have been light of the day.

I like to express my thanks to all the teaching, department of Mechanical Engineering. Finally I express my thanks to all of them, who gave valuable suggestions during the work.

\section{REFERENCES}

1. Umesh s ghorpade, D. S. Chavan, Vinaay patil, Mahendra gaikwad, "finite element analysis and natural frequency optimization of engine bracket" IJMIE, Vol-2, Iss-3, 2012. 
2. Babu, M. Sudheer, and V. Mahalakshmi Naidu. "BRTS Performance and Evaluation of Vishakhapatnam." TJPRC: International Journal of Traffic and Transportation Engineering \& Research (TJPRC: IJTTER) 2. 1, Dec 2017, 23-34

3. Mohd. Tanveer akthar, "design and analysis of fuel tank” IJRITCC, Vol-3, Iss-2, Feb- 2015

4. T, Kandasamy, S. Rakheja, and A. K. W Ahmed, "an analysis of baffles designs for limiting fluid slosh in partly filled tank trucks" the open transportation journal, 2014.

5. Murat kucumen, serdar ozkan, cuneyt dagdeviren, "fuel tank design and optimization for diesel commercial vehicles according to ECE R34 directives" otekon 2014.

6. Suresh, B., N. Venkat Rao, and G. Srinath. "Evaluation of engineering properties of flexible Pavements using plaxis software." International journal of mechanical and production Engineering research and development (IJMPERD) Issn (p) (2018): 2249-6890.

7. Michael Davis, Zhingxing fu, Qunhui Han, Ivonne Rivas, Anna Zemlyanova, “optimizing fuel tank design for high speed vehicles" graduate student mathematical modeling camp June 9-12 2009.

8. Gajendra G, Prakasha A M, Dr Noor Ahmed R, Dr. K.S.Badrinarayan, “design and optimization of HTV fuel tank assembly by finite element analysis" IRJET, Vol-2, Iss-7, oct-2015.

9. Kumar, Anil, and Vinay Saini. "An Investigation of Localized Corrosion of AL 2024 under Fully Immersed Condition of Chloride (HCL) Media." International Journal of Mechanical and Production Engineering Research and Development (IJMPERD) 7.4, Aug 2017, 291-306

10. Monali Deshmukh, K R Sontakke, “analysis and optimization of engine mounting bracket” IJSER, Vol-3, Iss-5, May-2015.

11. Pavan B. chaudhari, Dr. D. R. Panchagade, "comparison of magnesium, aluminum and cast iron to obtain optimum frequency of engine bracket using finite element analysis" IJERA, Vol-2, Iss-5, sep-oct 2012.

12. Jasvir Singh Dhillon, Priyanka Rao, V. P. Sawant, "design of engine mount bracket for FSAE car using finite element analysis” IJERA, Vol-4, Iss-9(version 6), September 2014.

13. Phadke, Vaibhav, and Nikhil Titirmare. "Construction of Tunnels, by New Austrian Tunneling Method (NATM) and by Tunnel Boring Machine (TBM)." International Journal of Civil Engineering (IJCE) 6.6 (2017): 25-36.

14. T, Kandasamy, S. Rakheja, and A. K. W Ahmed, "an analysis of baffles designs for limiting fluid slosh in partly filled tank trucks" the open transportation journal, 2014.

15. Baseera Banushaik, I.Prasanna, "Design and Optimization of HTV Fuel Tank Assembly by Finite Element Analysis", IJMETMR, vol-4, iss-2, Feb-2017.

16. Masilamani.R, P.Suresh, P.Tamilazhagan, N.Madhavan, S.Ponnuswamy, "Design and Analysis of High Density Polyethylene Fuel Tank for Heavy Vehicles" IJIRSET, vol-5, Iss-7, April-2016 

